Research Commentaries: FoOd Systems Research Priorities over the NeXt 5 YeaRS

\title{
The role of food hubs in food supply chains
}

\author{
James Matson ${ }^{a}$ and Jeremiah Thayer ${ }^{b} *$ \\ Matson Consulting
}

\begin{abstract}
Submitted May 30, 2013 / Revised May 31, 2013 / Published online July 12, 2013
Citation: Matson, J., \& Thayer, J. (2013). The role of food hubs in food supply chains. Journal of Agriculture, Food

Systems, and Community Development, 3(4), 43-47. http://dx.doi.org/10.5304/jafscd.2013.034.004

Copyright (C) 2013 by New Leaf Associates, Inc.
\end{abstract}

\begin{abstract}
The dramatic rise of the "local foods" market and the need for sustainable local food value chains has correspondingly led to innovative solutions designed to meet this burgeoning demand. Food hubs are just one of the local entities increasing in number across the U.S. and being used to facilitate
\end{abstract}

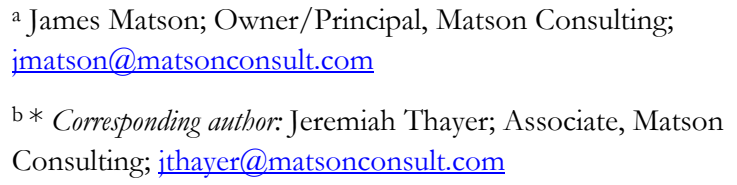

Matson Consulting; P.O. Box 661; Aiken, South Carolina 29802 USA; +1-803-233-7134

Authors' note: Matson Consulting is a business-consulting firm located in Aiken, South Carolina. Since its inception in 2001, Matson Consulting has adhered to its mission of offering business expertise that enables value-added agricultural ventures to succeed. Matson Consulting has worked with several examples of local agricultural complexes and assisted in the organization and infrastructure design of local food hubs. We have conducted numerous related feasibility studies, and working closely with these clients has enabled us to remain on the cutting edge of the emerging food hub trend. a closer connection between producers and consumers. Despite their popularity and increasing numbers, there exists comparatively little systematic research regarding food hubs; for example, investigation into the primary impetus for the formation of food hubs and local food chains, best practices, demonstrated impacts on the community, coexistence with current food supply chains, food safety, and the long-term viability of such entities have been explored only minimally in current literature. This commentary provides a brief context to present relevant questions for further research in the emerging trend of food hubs.

\section{Keywords}

agriculture, direct marketing, food desert, food hub, food safety, food systems, local foods, value chain

\section{Introduction}

There has been significant growth in the local foods movement in the United States in the past decade. The U.S. Department of Agriculture 
(USDA) service report, "The Role of Food Hubs in Local Food Marketing," cites the growth in direct-marketing channels and the increasing number of farmers choosing to utilize these channels as evidence of a local foods "phenomenon." As an example, the report states, "USDA's Agricultural Marketing Service lists 7,864 U.S. farmers' markets in operation in 2012, up from 7,175 the previous year, for a 1-year increase of nearly 10 percent." The same report also highlights USDA Economic Research Service figures showing that "local food sales through all marketing channels in the United States grossed [US] $\$ 4.8$ billion in 2008" (Matson, Sullins, \& Cook, 2013, p. 8).

The number of farmers' markets has nearly tripled over the last 15 years (USDA, 2012), and further evidence of the growth in local foods is represented by the significant amount of policy and support initiatives that have been enacted, such as the USDA's "Know Your Farmer, Know Your Food" initiative. According to the initiative's website, all 50 states have agricultural branding programs highlighting products sourced or made within the state; almost 200 food policy councils have been established; the National Restaurant Association has deemed local foods as one of the top trends every year since 2009; and there are approximately 220 food hubs operating across the nation, a 68 percent increase since 2008 (USDA, 2013).

Food hubs have been developed as a way to connect multiple producers to mid- and large-scale wholesale purchasers as well as individual customers more efficiently. The food hub concept has blossomed and has emerged as a logistical vehicle that facilitates a local food supply chain.

The USDA's working definition of a food hub includes "a business or organization that actively manages the aggregation, distribution, and marketing of source-identified food products primarily from local and regional producers to strengthen their ability to satisfy wholesale, retail, and institutional demand" (Matson et al., 2013, p. 5).

While national attention to food hubs and their benefits and roles in a community has grown, only a scarcity of systematic research is available regarding the growth, size, sales, or business structure of food hubs in the United States, as well as their impact on or role in traditional commodity food supply chains.

\section{What Is the Primary Driver for Food Hubs?}

In marketing, all demand is considered to be derived at some point from the demand of consumers. With regard to food hubs, it appears that interest in local foods (the locavore phenomenon) is a primary driver for the creation of food hubs.

However, there may be other undiscovered drivers that also fuel the increase and focus on entities of this type, including traceability, food attribute retention, energy consumption and food miles, and flavor and taste arising from local soils and climate similar to the terroir of wines.

\section{Questions for Further Research}

What primary drivers are fueling the local food movement and the establishment of food hubs? Are these drivers based more on a social mission or monetary incentives? Identifying the source of consumer demand can enable food bubs and other local foods entities to tailor the marketing of their products to match the values of consumers, and better serve their communities by offering additional services that can contribute to long-term profitability.

\section{Viability}

Given the broad range of social and nonmonetary goals exhibited by local foods entities, it can be difficult to measure the success of these ventures based on economic profit. Goals that center on social or ethical missions rather than financial profitability seem to be a feature of local food ventures in general, and food hub ventures specifically. Based on information gathered from our own internal survey work, numerous local food entities have sales that would indicate an ability to be economically profitable, but these same entities have enlarged operations at each point where they may have been able to remain of a certain size and achieve profit.

Local food ventures often measure success by the ability to return benefits to stakeholders, increase the reach of their operation (number of customers served), or provide services to producers that enhance their longevity and profitability. Thus they serve almost as public institutions for the common good. This business form is in 
stark contrast to the profit-driven model exhibited by the rest of the U.S. food supply chain. Fueled by low margins and high volume, commodity food systems generally relegate any type of social mission to a secondary concern.

\section{Questions for Further Research}

In the future, as consumers become increasingly willing to pay for local foods, existing commodity food chain players will most likely move to include local foods and more socially oriented, mission-based goals into their business structures. What is the role of food hubs and what is their effect on the current food supply chain? How do food hubs fit into the existing infrastructure of food supply chains? Is there a way for these entities to remain viable over the long term, or are they merely a current trend that will decline as the existing food supply chain incorporates the new demand for local foods? Each of these questions requires further investigation and research in order to answer satisfactorily. Examples of traditional food supply companies partnering with local food hubs exist and display an interesting symbiosis between what would appear to be two competing ideals.

\section{Food Hub Scale}

Though most food hubs are on the small end of the business spectrum in the food logistics industry, there seem to be significant scale effects involved in their operations. Smaller, more nascent ventures often utilize strategic partnerships or funding from grants and/or foundations in order to establish themselves and their operations. Many continue this method in order to remain operational. Often, food hubs view these financial partnerships as yet another means of knitting communities with the social mission of local foods through their financial involvement. Entities operating at the larger end of the scale of infrastructure built around the aggregation and delivery of foods often utilize outside partnerships or agreements as well.

At this point in time, the authors of this commentary are unaware of a truly national-scale food hub supply chain sourcing local foods. Due to the definition and underlying mission of food hubs and the local food movement in general, this may not even be a possibility.

\section{Questions for Further Research}

Are there certain services that need to be incorporated for food hubs at specific scale points, or are there certain services that should not be considered below a certain scale size? Does a place exist for food hubs only at a local and regional level? Are there constraints on the ultimate size and scale that a food bub can achieve while still fulfilling its underlying mission? Is there a minimum scale point at which food hubs are able to operate at optimum efficiency, while still taking into account their social mission as well as the need to be financially self-sustaining?

\section{Food Safety}

Food safety is a huge issue in the food industry as a whole, and is becoming a larger issue than ever before for those involved in food supply chains. These issues affect all levels of the chain, including consumers, intermediaries, and producers. Their impacts on activities, costs, and traceability will continue to grow with the increase in food safety rules and regulations.

Safety certifications will become a mandatory part of doing business for local food ventures. What remains to be seen is the impact that enforced food safety legislation and its associated costs will have on producers, especially those new or small-scale producers without access to large amounts of capital, infrastructure, or other resources that allow them to comply with new and existing legislation without prohibitive expenses.

While there is some pressure from wholesaletype customers regarding food safety, this mostly seems to be driven from liability concerns rather than the derived demand of customers requiring these safety protocols. Most ventures dealing directly with end consumers see very little request for "safety certified" products, making the ventures less concerned with achieving any high level of food safety certification.

Food hubs that focus primarily on wholesale and institutional customers are on the front line of dealing with new requirements in the current market; however, through internal research and survey work, it has been found that some farmers' markets in the western U.S. have started requiring safety certifications from vendors, indicating that food safety will soon include all producers, regardless of their scale or intended customer. 
Another major driver, depending on the end customer, is the need to have liability insurance policies in place. Some customers, especially larger institutional customers, require some type of insurance as a prerequisite for doing business.

\section{Questions for Further Research}

What is a reasonable path that could be taken to achieve both the goals of food safety as well as sustainability of smaller food producer ventures? Is there a market food bubs can access that does not require food safety certifications to be in place as a condition of sale? How should food hubs address the issue of food safety, especially since their primary sources of supply are often small-farm producers?

\section{Food Hubs and Transfer of Market Signals}

Food hubs provide a much shorter supply chain from producer to consumer than the traditional commodity supply chain. From both a producer and consumer perspective, food hubs and their shortened supply chain allow for the more efficient transfer of market signals, both from an attribute and information perspective, as well as from a supply and demand perspective.

\section{Questions for Further Research}

How can the efficient transfer of market signals be utilized to increase the economic sustainability of food bubs and other local foods entities? Does the shortened supply chain of local foods offset the efficiency of traditional commodity suppliers enough to be an acceptable alternative? What lessons can the existing food chain industry learn from local food hubs?

\section{Food Hubs as a Tool for Community Revitalization}

As highlighted in the journal article "Money and Mission: Moving Food with Value and Values," written by Adam Diamond and James Barham in 2011, the agriculture industry has experienced dramatic increases in production efficiency in the last 80 years, but this efficiency has lead to fewer and fewer farmers sustaining an ever-increasing percent of the population (Diamond \& Barham, 2011).

In the past, rural communities typically had businesses such as local canneries or local cream- eries. With increases in technology, operations of this type eventually disappeared due to the rise of large regional factories. The loss of these businesses at the local level and their corresponding move to regional entities negatively affected local communities in many ways.

The recent consumer interest in locally sourced and locally finished foods - the locavore trend has shifted the focus to address characteristics of the existing food system in order to promote healthy and sustainable local communities, a goal that must involve more than just mass production of commodity food at the cheapest price. This focus also includes concerns about the philosophy and long-term effects that a sustainable food system can have on a community.

Food hubs make use of the intersection of social values and consumer demand to simultaneously increase consumer access to local foods and increase the value and profitability of local food producers by preserving the food attributes desired by these same consumers. Increased profit for local producers and increased production in turn directly impact a local community through the retention of local dollars.

Many food hubs focus on social change more than economic profit. This secondary approach has proven successful as evidenced by the longevity of several food hub ventures throughout the country. One example of this social outlook and the positive benefits it can have is the ability of local food chains, such as food hubs, to affect communities by addressing the needs of food deserts. By definition, food hubs working to address the needs of a food desert are engaging in community revitalization. ${ }^{1}$

\section{Questions for Further Research}

Asking in what ways food bubs and local food supply chains can affect community revitalization also leads to other questions. What scale of producers is necessary to

\footnotetext{
1 The U.S. Department of Health and Human Services (USDHHS) defines food deserts as "communities, particularly low-income areas, in which residents do not live in close proximity to affordable and healthy food retailers. Healthy food options in these communities are hard to find or are unaffordable" (USDHHS, 2011, "What is a food desert?" para. 1).
} 
support the functions of a food bub? What mix of producers and products is necessary? Do these entities work on any scale level, or is there a maximum efficiency point? Do local food chains and food hubs operate best with a certain number of producers and level of crop variety? Are there regions of climate and topography that lend themselves better to the establishment of food hubs and local food supply chains? What are the policy and support initiative implications for local, regional, and federal programs? What level of support may be necessary to apply the theories learned through research to encourage the growth of local foods and food hubs?

\section{Conclusion}

From fulfilling a specific social mission to achieving independent financial profitability, food hubs are positively affecting both their member producers and the communities in which they are located in numerous ways. Though much remains to be learned about them, food hubs continue to be one of the most exciting innovations in the local foods supply chain.

Because of their adaptability in function, a variety of metrics might be applied to determine whether a particular food hub is a "success." No single measurement can be applied to all food hubs, as each must be measured by its success or failure in achieving its own underlying goals.

While the logistical aspects of creating a local supply chain are numerous and warrant further study, local food hubs have been a major vehicle for addressing several of these aspects in a positive way. Policy at the federal level seems to support the continuance of such solutions; while literature and initiatives are growing, a stark lack of statistics regarding successful operations, size, scale, and number of food hub entities still exists.

The sustainability and widespread implementation of local food supply chains is not necessarily exclusive of the current large-scale commodity nature of the U.S. food industry. Indeed, food hubs that are able to find a niche for themselves within the existing food system seem to have had the greatest success over time. Each system has its place, and in turn addresses a specific set of customer and producer needs.

It is the authors' opinion that taking a collaborative view and working to increase the amount of available information regarding the growth and benefits of food hubs as a local food supply chain solution will produce the best chance for long-term food chain sustainability. Additional research is necessary to fully explore the exciting possibilities that exist for local foods producers in today's food industry.

\section{References}

Diamond, A., \& Barham, J. (2011). Money and mission: Moving food with value and values. Journal of Agriculture, Food Systems, and Community Development, 1(4), 101-117. http://dx.doi.org/10.5304/jafscd.2011.014.013

Matson, J., Sullins, M., \& Cook, C. (2013). The role of food hubs in local food marketing (USDA Rural Development Service Report 73). Washington, D.C.: U.S. Department of Agriculture. Retrieved from http://www.rurdev.usda.gov/SupportDocuments/ USDAReportFoodhub2013.pdf

U.S. Department of Agriculture [USDA]. (2012). Farmers Market Growth: 1994-2012 [Graph]. Retrieved from http://www.ams.usda.gov/AMS v1.0/ams.fetchTemplateData.do?template $=$ Templa teS\&navID $=$ WholesaleandFarmersMarkets\&leftNa $\mathrm{v}=$ WholesaleandFarmersMarkets\&page $=$ WFMFar mersMarketGrowth\&description=Farmers $\% 20 \mathrm{Mar}$ ket $\% 20$ Growth\&acct $=$ frmrdirmkt

USDA. (2013). Know Your Farmer, Know Your Food: Our Mission. Retrieved July 9, 2013, from http://www.usda.gov/wps/portal/usda/usdahome ?navid=KYF MISSION

U.S. Department of Health and Human Services [USDHHS]. (2011) Healthy Food Financing Initiative, "What is a food desert? How do I locate one?" Retrieved May 21, 2013, from http://www.acf.hhs.gov/programs/ocs/resource/ healthy-food-financing-initiative- 0 